\title{
A Reversal Theory Analysis of Psychological Responses During Sports Injury Rehabilitation
}

\section{Joanne Thatcher, John Kerr, Kristy Amies, and Melissa Day}

\begin{abstract}
Context: Few studies have examined psychological and emotional processes in injury rehabilitation from a longitudinal, theoretically framed perspective. Objective: This study explored the applicability of Reversal Theory to examine these processes. Setting: University of Wales, Aberystwyth, UK. Participants: Three severely injured athletes; two were female (karate and judo) and one was male (hockey), aged 20 to 28. Main Outcome Measures: Fortnightly interviews after participant's initial consultation with a sports therapist, until complete physical rehabilitation. Results: Supported the use of Reversal Theory in this context (eg, as a means of understanding the origins of athletes' emotional responses to injury and changes in these responses throughout rehabilitation). Conclusions: Suggestions for future research are made (eg, examining the consequences of emotional and metamotivational states for athlete behavior and recovery outcomes during rehabilitation). Key Words: longitudinal, emotions, metamotivational, qualitative, phenomenological
\end{abstract}

When athletes suffer sports-related injury they are likely to experience a range of negative psychological and emotional responses such as fear of reinjury, loss of identity, anger, frustration, depression, and disbelief..$^{1-3}$ Other studies have also reported more positive responses, such as philosophical acceptance and personal growth., Moreover, during recovery from sports injury, psychological factors such as attributions for rehabilitation progress have been shown to be related to perceived rate of recovery. ${ }^{5}$ Although this evidence provides useful knowledge concerning athletes' psychological responses to injury, in general, this early research is limited by three main factors: (1) a tendency to measure responses using closed questionnaires that limit the scope of potential responses available to participants, (2) a reliance on one-off retrospective accounts that do not permit in situ exploration of athletes' responses as they occur and change over time, and importantly, (3) a tendency toward descriptive analysis in the absence of a guiding theoretical framework.

Joanne Thatcher is with Aberystwyth University, Wales, Department of Sport \& Exercise Health Science. Melissa Day is with the University of Chichester, School of Sport and Exercise Science. John Kerr is with Kokushikan University in Japan, and Kristy Amies is the Abersytwyth Sports Therapy Clinic. E-mail: jet@aber.ac.uk. 
More recent work has begun to address these limitations. For example, Morrey and colleagues ${ }^{6}$ conducted a longitudinal examination of psychological responses in anterior cruciate ligament injured athletes. They suggested that the significant mood changes they observed in these athletes may have a detrimental impact on early rehabilitation. Tracey ${ }^{7}$ interviewed injured athletes at injury onset, and 1 and 3 weeks postinjury, about their emotional and cognitive responses to moderate to severe injuries. Her results were interpreted within the framework of the Integrated Response Model $^{8}$ and indicated broadly that as this model suggests, cognitive appraisals are highly influential determinants of an athlete's emotional response to injury. Although this study examined in situ, longitudinal changes in emotional responses to sports injury, Tracey ${ }^{7}$ did acknowledge that research is required that includes more than just three data points to allow more in-depth exploration of the athlete's psychological and emotional experiences during rehabilitation from injury. Vergeer ${ }^{9}$ carried out a recent study that involved eight interviews with an injured athlete, conducted over a twenty-week period. The study examined temporal changes in the athlete's mental representations of his injury. Five dominant and interrelated themes were revealed: awareness of the injury, mental imagery associated with the injury, the athlete's mental model of the state and consequences of the injury, the athlete's mental representation of the recovery process (mental itinerary), and the importance of the athlete's desired self-concept. Focusing on the return to sport following serious injury, Podlog and Eklund ${ }^{10}$ interviewed athletes on three or four occasions spanning the period from just prior to the athlete's return to competitive sport to approximately 6 to 8 months afterward. The authors identified the fulfillment of competence and relatedness needs as salient motives in the athlete's return to sport and highlighted the importance of athlete autonomy in controlling the timing of this return.

Recent work, nevertheless, has identified that research in this area is still largely atheoretical. ${ }^{10}$ In a study of interpersonal relationships in sport, Males and associates ${ }^{11}$ advocate the application of established and previously verified theories from mainstream psychology to study sport psychology phenomena. They suggest that the use of a qualitative method in conjunction with a well supported and established theoretical framework offers the advantage of obtaining in-depth qualitative data that can be interpreted using a previously verified theoretical framework. Along these lines, Podlog and Eklund ${ }^{10}$ used Self-Determination Theory ${ }^{12}$ in their investigation into the seriously injured athlete's return to competitive sport. A number of previous authors have also emphasized the need for qualitative interview based methodologies that capture the athlete's subjective experience in examinations of psychological responses to sports injury. ${ }^{13-16}$ Considering these two arguments, it is clear that qualitative interview based research that is guided by an established and verified theoretical framework may add to our understanding of athletes' psychological responses to injury.

A potentially useful theory in this area of research is Reversal Theory. ${ }^{17}$ The rationale for using Reversal Theory in this context is supported by a number of factors. First, as has been advocated by Males and colleagues, ${ }^{11}$ this theory has been previously tried and tested both empirically and in its practical application across a diverse range of topics and contexts, such as health, religion, education, relationships and sport. ${ }^{18}$ Second, previous authors have suggested that investigations into athletes' psychological and emotional responses to injury should aim to capture the 
athlete's subjective experience. ${ }^{13-15}$ The starting point of Reversal Theory is subjective meaning ${ }^{19}$ with an emphasis on the individual's interpretation of the subjective meaning of his or her experience, therefore addressing previous calls to examine the athlete's own subjective experience of sports injury. Third, the study of athletes' psychological responses to sports injury requires a framework that will embrace the dynamic nature of this response and lend itself to longitudinal examinations of this phenomenon. Reversal Theory offers a structural framework within which the dynamic nature of the individual's psychological, emotional, and motivational experience is central. As Apter ${ }^{18}$ has stated, "at the heart of the theory therefore is a focus on the individual over time" (p. 5, original italics).

\section{Reversal Theory}

According to Reversal Theory, ${ }^{18}$ motivation is central to our experience, providing an internal framework for behavior, cognition, and perception. Our current motivation and the ways in which we interpret our experiences are determined by our current motivational state. Apter ${ }^{18}$ has identified four pairs of motivational states, as depicted in Table 1. The two states in each pair are bipolar opposites, thus only one state from each pair can be operative at any one time. While opposing states cannot be experienced simultaneously, states from different pairs do combine and are associated with specific pleasant and unpleasant emotions: telic-conformity (anxiety, relaxation), telic-negativism (anger, placidity), paratelic-conformity (excitement, boredom), paratelic-negativism (provocativeness, sullenness), auticmastery (pride, humiliation), autic-sympathy (gratitude, resentment), alloic-mastery (modesty, shame), and, alloic-sympathy (virtue, guilt). The experience of unpleasant emotions is stressful.

Current experience is an important aspect of Reversal Theory as the theory emphasizes that individuals regularly switch between opposing motivational states (eg, telic to paratelic). These reversals are induced by three reversal agents: environmental events, frustration at not meeting current motivational needs, and satiation of time spent in one state. Thus, intraindividual change in subjective experience is fundamental to Reversal Theory. Although emphasizing the state-based nature of motivation, Reversal Theory proposes that each individual will demonstrate a general tendency toward one of the motivational states in each pair. This is known as motivational dominance. It is also possible that over a defined period of time,

\section{Table 1 Summary Definitions of Motivational States Within Each Pair}

\begin{tabular}{llll}
\hline Means-Ends & Rules & Transactions & Relationships \\
\hline $\begin{array}{l}\text { Telic (serious) state } \\
\text { Goal and future oriented }\end{array}$ & $\begin{array}{l}\text { Conformist state } \\
\text { Maintaining rules } \\
\text { and conforming }\end{array}$ & $\begin{array}{l}\text { Mastery state } \\
\text { Competitive, } \\
\text { valuing strength, } \\
\text { and toughness }\end{array}$ & $\begin{array}{l}\text { Autic (self-oriented) state } \\
\text { Focusing on self and not } \\
\text { identifying with others }\end{array}$ \\
$\begin{array}{l}\text { Paratelic (playful) state } \\
\begin{array}{l}\text { Spontaneous, now } \\
\text { orientation }\end{array}\end{array}$ & $\begin{array}{l}\text { Negativistic state } \\
\text { Rebellious and } \\
\text { nonconformist }\end{array}$ & $\begin{array}{l}\text { Cooperative, valuing } \\
\text { tenderness }\end{array}$ & $\begin{array}{l}\text { Focusing on and } \\
\text { identifying with others }\end{array}$ \\
\hline
\end{tabular}


such as injury rehabilitation, one or more pairs of states may be more salient to the individual than other bipolar state pairs, meaning that the individual may be more aware of whichever of these two states in a pair is operative than of other concurrent operative states.

Reversal Theory is therefore well suited to describe, explain, and predict the emotional changes that are experienced as a result of injury and ultimately may help to understand the motivational factors that are associated with successful rehabilitation from injury. A wealth of research has previously demonstrated support for the structural framework of experience that has been proposed in Reversal Theory, ${ }^{18}$ although the theory is yet to be employed within the context of rehabilitation from sports injury. It appears also that there is substantial scope for more longitudinal, theoretically framed, and in-depth studies into the emotional and psychological consequences of sports injury. The aim of the current study, therefore, was to conduct an initial, exploratory investigation into the application of Reversal Theory for examining the longitudinal changes in injured athletes' psychological and emotional experiences during injury rehabilitation.

\section{Methods}

\section{Participants}

Participants were purposely selected from patients attending a university sports injury clinic. When a patient with a severe injury presented to the sports therapist, she requested the athlete's participation in the study, if the athlete rated the importance of rehabilitation from injury as high, to ensure that rehabilitation is important to them (this measure is described below). Severity was classified according to the National Athletic/Illness Reporting System..$^{20}$ A severe injury is classified as an injury that prevents an athlete from participating in practice/competition for more than 21 days. Details on the context of injury occurrence are provided in the Results and Discussion sections that follow. Although not a requirement for inclusion in the study, the three study participants exhibited contrasting motivational profiles, both in general and in the pattern of operative motivational states during the period of injury rehabilitation.

Amy (all names are pseudonyms) was a 23-year-old karate athlete and a member of the National students' squad. She had an anterior dislocation of the left shoulder and had been involved in karate for 3 years. Mary was a 27-year-old university level judo athlete who had a fracture to the fibula with ligament and tendon damage and had been involved in judo for 3 years. John was a 25-year-old university level field hockey player who had a grade II tear of the lateral collateral and posterior collateral ligaments of the knee and had been playing hockey for 9 years. All participants rated the importance of injury rehabilitation as 6 or $7 / 7$.

\section{Measures}

Motivational Dominance. This was assessed via the Motivational Style Profile $\left(\mathrm{MSP}^{21}\right)$. This scale includes 70 items with 14 subscales, each comprising 5 items. It is acceptable for researchers to retain only those subscales of current interest, as has been done in previous research. ${ }^{22}$ In this study, therefore, only 
those motivational states that are at the core of Reversal Theory were used ${ }^{18}$ : telic, paratelic, conformist, negativistic, autic-mastery, autic-sympathy, alloic-mastery, and, alloic-sympathy. To respond to each item, a temporal six point scale is used that is anchored by 1 (never) and 6 (always). Based on a UK sample, Apter and colleagues $^{21}$ have demonstrated that the MSP has acceptable face, construct and concurrent validity, test-retest reliability, and internal consistency of its subscales. For instance, Cronbach's alpha coefficients ranged from 0.68 to 0.89 and test-retest correlations from 0.71 to 0.92 .

Importance of Rehabilitation. This was assessed by one item taken from the Sports Injury Rehabilitation Beliefs Survey. ${ }^{23}$ This was employed as a descriptive measure to assess the importance of injury rehabilitation to the participants: "Being fully recovered from injury is very important to me." The SIRBS employs a 7-point Likert-type response scale anchored by 1 (very strongly disagree) and 7 (very strongly agree).

Emotional and Psychological Responses to Injury. These were explored during unstructured interviews. The purpose of the interviews was to gain an account of athletes' experiences during rehabilitation that would provide a basis for analysis of these experiences using a Reversal Theory framework. The interviews were unstructured to ensure that questions and responses were not biased toward Reversal Theory constructs and in line with the Reversal Theory principle that the individual's own phenomenology is central to understanding his or her experiences. The initial interview therefore drew upon existential phenomenological principles of interviewing, ${ }^{24}$ beginning with an opening prompt, "Tell me how your injury occurred" and subsequent interviews began with the prompt, "Tell me how things have been since we last met." Questions that followed were based on the participants' responses and followed the topics of discussion that they raised to obtain further information on the athlete's overall experience, encompassing emotional responses, cognitions, behaviors, significant events during rehabilitation, and interactions with others. The interviewer endeavored to ensure that questioning was not led by her understanding and awareness of Reversal Theory states and concepts (see Trustworthiness section for further comment on this issue). Participants were not asked to discuss Reversal Theory states and concepts per se; instead they were asked to discuss their own experiences, behaviors, cognitions, and emotional responses to these experiences. These explanations were then analyzed to determine if they could be interpreted within a Reversal Theory framework. To ensure that each interview had covered all topics and experiences that were important and relevant to participants, at the interview's conclusion they were asked to consider anything that they had experienced since the previous interview that they felt was important but had not yet been discussed. An unstructured interview poses the dilemma that respondents may not discuss the issues with which the researcher is concerned (eg, emotional responses) while simultaneously offering the benefit that the researcher does not impose his or her agenda on the respondent. In the current study, all participants did discuss all constructs of interest to the researcher, which is not surprising given the centrality of these constructs to the injured athlete's experience. Moreover, this risk was outweighed by the importance of not biasing participants toward Reversal Theory constructs and proposals in an exploratory study of the application of this theory within this context. All interviews were conducted by the first author who has 
attended postgraduate and postdoctoral training in qualitative research philosophy, design, data collection, and analysis. She has supervised qualitative doctorate level research and has published qualitative research in peer-reviewed journals.

\section{Procedures}

The study was approved by the University Ethics Committee, in the spirit of the Helsinki declaration. Participants were recruited from a University Sports Injury Clinic at their intake appointment via a request from the sports therapist. After providing informed consent and during their intake appointment, participants completed the $\mathrm{MSP}^{21}$ and one item from the SIRBS. ${ }^{23}$ Immediately after, and every two weeks following intake, participants were interviewed until the athlete was permitted to return to normal training and competition. This period therefore covered the following four stages of rehabilitation ${ }^{25}$ : Initial stage (non-weight bearing: the aim is to increase range of motion and become pain free); Intermediate stage (partial through to full weight bearing: aim is to restore full range of motion); Advanced stage (no marked difference between healthy and injured areas); and Return to sports stage (patient should be as good as or better than before injury before return to sport: coach and therapist must be happy with full training form).

Interviews lasted between 30 minutes and 2 hours. Five interviews were completed with Amy and 7 with Mary and John, spanning a period of 10 weeks for Amy and 14 weeks for Mary and John. These participants also provided data as part of a larger ongoing study to be reported elsewhere.

\section{Data Analysis}

Primary data analysis employed the following steps, in line with procedures utilized in previous research ${ }^{26,27}$ for Reversal Theory-based qualitative data analysis:

1. Each transcript was read and reread to refamiliarize with the content and tenor of the interview.

2. To grasp the overall emphasis of the transcript, case summaries were produced for each of the interviews.

3. Individual quotations from interview transcripts were then highlighted that represented individual units of meaning. ${ }^{28}$

4. These quotations were then deductively examined for evidence of Reversal Theory states, associated emotions, and reversal agents, based on established definitions. ${ }^{18}$

5. A written explanation was provided for each categorization. To provide overall coherence and to assist with secondary analysis (see later comments), these categorizations were grouped under thematic headings such as adherence to rehabilitation and interaction with others.

6. A summary sheet was compiled for each interview that listed states, emotions, reversals and reversal agents, accompanying explanations for these categorizations and the quotation on which these were based. The most salient state combination was then identified at each interview point. This was based on both the frequency of occurrence of the states, as listed on these summary sheets, and overall meaning and emphasis of the individual's experience as indicated in each transcript. 
7. The most salient motivational states throughout the injury rehabilitation period were identified for each participant based on the frequency and emphasis of the motivational states experienced across the whole period of rehabilitation.

A second analyst then read each transcript for overall meaning and used the summary sheets and interview transcripts to check on the initial categorization of data. She highlighted where she felt that the first analyst had misclassified any data or had failed to classify any relevant data from the transcripts. Of the 19 transcripts there were only 15 such instances and these were resolved through discussion until $100 \%$ agreement was achieved. The second analyst has received postgraduate training in qualitative research philosophy, design, data collection and analysis, and is currently conducting a qualitatively based doctorate. She has published qualitative research in peer-reviewed journals. She was made aware of basic concepts and definitions within Reversal Theory but was not an expert in this area. Thus she was competent in qualitative data analysis and conversant with Reversal Theory allowing her to play a key role in safeguarding against unwanted bias toward Reversal Theory by the first interviewer. Her checks on the interview transcripts identified that this potential bias had been successfully avoided.

Trustworthiness. Checks for interviewer bias were also made by the second analyst. Trustworthiness of data analysis was addressed in three ways: recording a detailed written trail of the primary analysis that was used for audit by the second analyst; secondary analysis of the data (peer debriefing); and the presentation of data interpretations, in the form of prose discussions of the athlete's experiences, including how these were interpreted in Reversal Theory terms and quotes from the athlete to support these interpretations (member checks). Although participants were furnished with Reversal Theory definitions and basic concepts, their role was not to check on the Reversal Theory analysis of the data. Instead they were asked to determine if the researchers' interpretation of their experiences matched their actual experiences. No participants identified any inaccuracies in these interpretations following member checking. Finally, the results section provides both rich contextual information concerning each participant's experience and uses quotations from the participants to illustrate the researchers' interpretations of these experiences.

\section{Results}

This section will first consider the context in which each athlete's injury occurred and each athlete's dominant motivational style. Second, case by case longitudinal changes in metamotivational states will be considered, followed by common observations in participants' responses to their injury.

\section{Amy (Karate Athlete, Dislocated Shoulder)}

Injury Occurrence. Amy's injury occurred during a karate tournament in a sparring bout with an opponent against whom Amy had been wrongly placed by tournament officials. In her view, these same officials had previously caused other athletes in the tournament to be injured by mismatching opponents. Amy's injury occurred when her opponent, who she identified as, "way too strong, she'd already injured people before ..." kicked her shoulder and followed it up with a punch, leading to 
immediate dislocation. She maintained her telic-conformist approach to competition even when injured:

Because it was for the bronze medal that fight, because I didn't kick up that much of a fuss, I mean I kind of stopped and went what, it's dislocated. Ow! But, because I didn't kind of say it was all her fault, they kind of took it as though I couldn't carry on as opposed to she's disabled me.

Reflecting on the injury in interview one, however, her telic-negativism and accompanying anger were apparent:

But they read it wrong and I should have been fighting . . . instead of this girl who'd actually hurt me so it was a big mess so I'm having a good old legal battle with that.

Also evident were her autic-sympathy and resentment concerning the way in which her injury had occurred: "So that makes it even worse knowing that I shouldn't have been up against her."

Motivational Style. Based on her MSP results, Amy is telic, conformist, alloic, and sympathy dominant. Thus her dominant motivational orientation is to want to be engaged in serious, purposeful activities, to conform to rules, and to identify cooperatively and sympathetically with others. However, during the period of injury rehabilitation, the telic, conformist, mastery, and autic states were most often operative. Therefore she experienced two changes in motivational salience during this period: from alloic-sympathy to autic-mastery, reflecting a shift from identifying cooperatively with others to a competitive, mastery oriented focus on herself.

\section{Mary (Judo Player, Fractured Ankle)}

Injury Occurrence. Mary's injury occurred during the warm-up at a training session where her judo coach suggested that everyone perform back flips:

I was doing judo, we were just in the warm up and well, the thing is with judo there's lots of guys and they want to do things, you know, so we were doing back flips and I don't think they really thought about the risk involved and I thought I was quite fit.

The injury occurred as she landed awkwardly, resulting in an uneven distribution of weight bearing through her ankles, placing more stress on one ankle, leading to her injury. Reflecting on the incident in her first interview, she stated, "I almost didn't do it, but you know, you've got everybody there having fun and you just do it." When trying the back flips, her motivation was likely to have been paratelic, conformity and alloic-mastery-oriented, as she joined with other male judo players in trying to master the fun activity. However, later after a reversal from alloic to autic-mastery took place, she felt humiliated as she thought about her lack of personal strength and control and her inability to have acted independently by declining to take part.

Motivational Style. Her scores on the MSP indicated that Mary was paratelic, conformist, mastery and autic dominant. Thus her dominant motivation is to be 
spontaneous, to conform to rules, to value strength and competition, and to focus primarily on herself. Her most frequently operative motivational states during injury rehabilitation matched her dominance profile with the exception of the telicparatelic pair, reflecting a shift from a spontaneous, here and now orientation to a more serious future oriented motivation. The telic state replaced the paratelic state so that her motivation during this period was characterized by the telic, conformist, autic, and mastery states.

\section{John (Field Hockey Player, Ligament Damage)}

Injury Occurrence. John's injury occurred, not during a field hockey game, but during a friendly rugby tournament. His injury occurred during a run down the wing as he turned to receive a pass from a teammate that was placed behind him. As he turned, he simultaneously braked and his boot studs stuck in the ground, causing his knee to rotate in one direction and the rest of his body in the other direction. He began the match in a paratelic-conformist state combination, accompanied by high arousal and feelings of excitement, that allowed him to experience the tournament in a pleasant paratelic manner, "I just went down and ended up playing for a couple of friends' teams and I was the man on the wing and I was thinking fantastic I'm on for a try."

His injury (an environmental event) caused a reversal from paratelic- to telicconformity, with high arousal then experienced as anxiety: "I was worried about it in terms of having looked into it and the sort of problems that can result from it and, having had an injury on my left knee in the past, I was a little bit anxious." However, the immediate social support and the (alloic-sympathy-oriented) humor offered by his friends (an environmental event) soon caused a reversal back to paratelic-conformity:

And then once I sort of got off the field and was sort of starting to get the treatment, got the ice on it, the pain started to ease a little bit and I started to relax, a couple of friends were there as well, sort of laughing and joking about it and I sort of relaxed then a lot and was able to laugh about it.

Motivational Style. MSP results indicated that John's motivational style was dominated by the paratelic, conformist, alloic and sympathy states. Thus his dominant motivational orientation is to be spontaneous, conform to rules, and to identify and focus on cooperation with others. His most frequently experienced motivational states throughout injury rehabilitation differed in some ways from his general motivational style and comprised the telic (rather than paratelic), conformist, autic (rather than alloic), and sympathy states. Thus his dominant style shifted from a spontaneous, here-and-now focus to a serious, future oriented one and a tendency to focus on himself rather than on others.

\section{Longitudinal Responses to Injury}

Table 2 provides a summary of the longitudinal changes in these athletes' most salient state combinations and associated emotions during their rehabilitation. This section presents a Reversal Theory interpretation of the athlete's experiences 
over time followed by an illustrative quote or quotes from the athlete to support this interpretation.

\section{Amy (Karate, Dislocated Shoulder)}

Amy's period of rehabilitation was shorter than John and Mary's, which may have contributed to the fact that, unlike these other two athletes, throughout her rehabilitation, autic-mastery had much greater salience. Like Mary, however (see below), in her initial interview, Amy reported a strong orientation toward auticsympathy (see Table 2). Apart from gratitude expressed at the support received from the sports therapist and a close friend, she mostly felt resentful. From her interview comments, it was apparent that this resentment stemmed from both the way in which her injury had occurred and the unsympathetic hospital staff who provided her initial treatment:

. . . because I was in my gee (karate uniform) as well, but the people at the hospital didn't help because they had this one lady there saying, "well if you will do these kind of sports" so I was just like, thank you . . .

Over the next 8 weeks, statements from interviews 2 to 5 suggest that Amy's most salient motivation was autic-mastery-based. Initially, however, at interview 2 , she was feeling humiliated because she was unable to participate in karate training and she was anxious that others might feel that she was faking her injury:

Table 2 Most Salient State Combinations and, Where Appropriate, Associated Emotions Experienced Across the Injury Rehabilitation Period

\begin{tabular}{|c|c|c|c|}
\hline Interview & Amy & Mary & John \\
\hline 1 (week 2) & $\begin{array}{l}\text { Autic-sympathy } \\
\text { (resentment) }\end{array}$ & $\begin{array}{l}\text { Autic-sympathy } \\
\text { (resentment) }\end{array}$ & $\begin{array}{l}\text { Telic-conformity } \\
\text { (anxiety) }\end{array}$ \\
\hline 2 (week 4) & $\begin{array}{l}\text { Autic-mastery } \\
\text { (humiliation) }\end{array}$ & Telic-conformity & $\begin{array}{l}\text { Autic-sympathy } \\
\text { (resentment) }\end{array}$ \\
\hline 3 (week 6) & $\begin{array}{l}\text { Autic-mastery } \\
\text { (pride) } \\
\text { Telic-conformity }\end{array}$ & Autic-mastery & $\begin{array}{l}\text { Alloic-sympathy } \\
\text { (virtue) } \\
\text { Autic-mastery }\end{array}$ \\
\hline 4 (week 8) & $\begin{array}{l}\text { Autic-mastery } \\
\text { (pride) }\end{array}$ & $\begin{array}{l}\text { Autic-mastery } \\
\text { Autic-sympathy } \\
\text { Telic-conformity }\end{array}$ & Alloic-sympathy \\
\hline 5 (week 10) & Autic-mastery & $\begin{array}{l}\text { Autic-sympathy } \\
\text { (resentment) }\end{array}$ & $\begin{array}{l}\text { Autic-sympathy } \\
\text { (gratitude) }\end{array}$ \\
\hline 6 (week 12) & & Autic-sympathy & $\begin{array}{l}\text { Paratelic- } \\
\text { negativism } \\
\text { Autic-mastery }\end{array}$ \\
\hline 7 (week 14) & & Autic-mastery & $\begin{array}{l}\text { Telic-conformity } \\
\text { Autic-mastery }\end{array}$ \\
\hline
\end{tabular}


... because they've seen me walking around . . . without the bandage on and everyone's asking when I'm coming back, and I feel like I' $m$ a fraud or something because nothing's stopping me-but there was.

Although she still felt some humiliation at being unable to participate in full training, Amy's main emotional response at interview 3 was the pride she experienced by making progress in her rehabilitation, helping to fulfill her autic-mastery need to feel she was on the road to recovery:

Brilliant because I've been on that red one [rehabilitation equipment] for two, no four weeks, I think because of the pain I had before, so I kind of stuck at the same grade but now I'm on the next one and I was like, yes!

The telic-conformist state combination was equally salient at this time and her pleasant feeling of pride was added to by telic-conformist-oriented feelings of satisfaction at achieving goals as she adhered to the therapist's advice and refrained from contact work:

I know that the club are kind of-Oh, you look like you're doing all right you could probably do it, and I probably could but I don't want to until she [therapist] gives me the all clear.

At interview 4, her increasing progress in rehabilitation and training situations led to increased feelings of being strong and tough, meeting her autic-mastery needs, and again resulting in pleasant feelings of pride: "I've started doing weights, which is great because I feel like I'm actually going to start getting my strength back."

In her final interview, with her injury fully rehabilitated, she was looking to the future and maintaining her functional autic-mastery orientation: "This is more important you know ... this is going to help me get better so I'm going to push myself harder to do this."

\section{Mary (Judo, Fractured Ankle)}

As Table 2 indicates, the autic state dominated Mary's motivational experience during her rehabilitation from injury. Initially, Mary's most salient motivational state was autic-sympathy, accompanied by an emotional response of resentment as her autic-sympathy needs were largely unmet. She expressed concern that her injury would never fully rehabilitate. Even so, her resentment stemmed mostly from the support she desired, but did not receive, from significant others (fellow athletes, her partner and medical personnel):

Well you're just a number really to them [medical personnel] it doesn't matter whether you're on crutches for six months or three months, to them it doesn't do [sic] any difference and that isn't very nice.

Mary's main orientation had switched to telic-conformity at the time of the second interview. This was evident in her adherence to prescribed rehabilitation and a conscious shift from a focus on sport to her teacher training course and securing a job on its completion. Interestingly, she suggested that the injury had affected her tendency to take risks and act spontaneously in the future, resulting in an overall 
tendency toward greater telic-conformity: “ . . there's things I will never do again, like taking risks, I don't think now I'll ever take risks again.”

In interview 3, Mary's autic-mastery needs were foremost. As was previously the case with her autic-sympathy motivation, now, due to her injury, she was largely unable to meet the autic-mastery needs that she had previously satisfied through judo training and competition. Although Mary's autic-mastery motivation resulted in a desire to feel personal strength, control, and toughness, she did not feel capable of achieving these goals:

But you know going back into it and going back into the sweating and things like that, because it is hard and I didn't realize, and it is . . . and until I see the results in judo it's going to be quite a hard time to go back into sport.

Both her telic-conformist and autic-mastery orientations remained strong at interview 4; however, while her telic-conformist goals could be met through her management of her injury and adherence to prescribed rehabilitation, she still could not train or compete. Autic-sympathy was, however, marginally more salient at this point and although some resentment was still evident toward some medical personnel who were treating her, she also expressed gratitude for the support and empathy she was receiving from her sports therapist: "She [therapist] just couldn't believe that I was still in so much pain and that my ankle was still so badly damaged."

Autic-sympathy remained Mary's most salient motivation over the following four weeks. At interview 5, this was accompanied by more feelings of resentment at the pain she was experiencing, the continuing impact of her injury on her daily life, the lack of care from the medical personnel who had initially treated her, and her concern that her injury would continue to affect her both physically and mentally:

... does it mean that I'm going to live now with a contact pain, which isn't the end of the world, it's not pain pain, but it's something you feel all the time. So is that it? You know is that going to be as better [sic] as I'm going to get?

By interview 6, Mary had returned to some modified judo training, but from her comments, her autic-sympathy state combination was still often operative and, it seems, did not allow her to engage fully in this activity. Her vulnerability and fear of reinjury led to her feeling weak and needing to protect herself when working with a partner. Physically, she was capable of taking part in judo training, but being stuck in the autic-sympathy state combination appeared to be associated with a kind of mental block that prevented her from becoming more fully involved:

... I'm there but I can't really acknowledge it. Now I can feel the bone twitching so I think, oh it's not quite there but you know sometimes it just cracks but every other bone or muscle does. But there's always something that comes back and says well maybe it's not mended ...

A stark contrast was apparent in the final seventh interview. The autic and mastery states were now Mary's most salient motivational combination. This spontaneous reversal, perhaps as a result of satiation, from autic-sympathy to autic-mastery allowed her to now feel mentally tough and in control, as the sympathy state no 
longer influenced her motivation: "I mean for some reason I don't know how that happened, but I just thought that's it, I'm not going to worry any more about it."

\section{John (Field Hockey, Ligament Damage)}

John's initial telic-conformity demonstrated his motivation to adhere to rehabilitation, manage his injury sensibly, and achieve full, long-term recovery: "I'm starting to take things fairly steady now, rather than rushing into it, if it means taking an extra week or two off work, then I'm quite happy to, I'll find money to cover that somehow."

Injury resulted in a high level of arousal for John, which was interpreted as anxiety when early medical treatment was perceived as inadequate. This anxiety was replaced with pleasant relaxation when his perception of his medical treatment improved with the introduction of a sports therapist to his treatment team.

By his second interview, autic-sympathy was John's most relevant motivation, coupled with strong feelings of resentment, fueled by the pain experienced during rehabilitation exercises, lack of concern from some medical personnel, and the realization that rehabilitation would be both lengthy and limiting:

Going to the fracture clinic ... that was initially what started putting me down because I was in such a foul mood. I'd been doing this work and paying for the treatment ... and he'd just gone, yeah, that seems OK. Which I was like well is there much point me bothering with this because they're not actually going to check it, the only way I'm actually going to be able to get better is if I sort it out myself.

Time out from training, competition, and work as a personal fitness trainer because of his injury gave John time to focus on his career plans, which, coupled with his rehabilitation progress, helped to satisfy his prominent autic-mastery needs at the time of interview 3:

I still feel there's a lot of progress in it like being able to walk up and down the stairs or go for a walk, you know. After the first sort of four or five weeks, I went for a walk across the field, and it's the first time I've been out for a proper walk.

John's comments indicate that alloic-sympathy motivation and feelings of virtue had become more prominent in interview 3:

So we've just been able to focus on each other [he and his girlfriend] and focus on ourselves as well, just do all the stuff that we want to do, rather than having to worry about fitting it in around everything. Because normally, a lot of the time she was having to fit around what I was doing, which was far too much basically ... so now I've just sort of taken back, reevaluated everything, spending time with friends, family, and that sort of thing just to sort of get back into the swing of things again and find out where the really important bits are.

In interview 4, it was even more so. John's focus shifted increasingly from himself and his own needs to his interactions with others and meeting their needs: 
Myself and [girlfriend's name] will go down [to the gym], that's been quite nice as well, because [girlfriend's name] has always been quite a gymophobe [sic], absolutely hated it and the first time we went there last week she was sitting there sweating before we went ... so I took her through it and she loved it.

John's autic-focus reemerged at interview 5, predominantly linked to the sympathy state. In Reversal Theory terms, this was evident in his concern for himself and feelings of weakness and poor self-confidence, his vulnerability to reinjury, and frequent attempts to protect himself from reinjury during a recreational football match:

It was good to get back in and get doing something again, but I could feel that my confidence was really lacking. I sort of made one or two half hearted attempts at changes of direction but that was it and I was sort of very ginger on it and I'd take myself off every five minutes.

Also evident was the gratitude he experienced for others' attention: “. . . and it's almost like people are interested in me, wanting to know how I was getting on, wanting to see me back. That gave me a real kick in terms of my teaching abilities and ... where they were wanting me back."

Between interviews 5 and 6 , John experienced minor reinjury that according to Reversal Theory, is likely to be related to his salient paratelic-negativism and his high alloic-sympathy needs. These motivational state combinations left John with a desire to be involved and identify with others, to rebel against medical advice and act spontaneously, something he had not done for some time. Thus, he unwisely took part in physical activities alongside High School students he was tutoring at summer school: "I wanted to get out and get involved with it and have a bit of a laugh and do something, and I wanted to have a bit of a run around anyway because I got fed up being stuck inside."

His salient autic-mastery needs were largely unmet at this point, evidenced by his humiliation at his deteriorating fitness and physique: "I' $m$ feeling a bit conscious of, hang on I've had three months off I need to focus a little bit more on controlling my weight and trying to keep some sort of fitness going."

At the final interview, John identified a return to telic-conformity, as shown by his adherence to rehabilitation activities and restrictions and setting goals for his return to competitive sport: ". . I f feel sort of quite comfortable, I know where the limits are, I pushed the limits too far earlier on so I've taken a step back then from it so I need to take it steady getting back into it."

\section{Observations Across Participants}

Motivational Style and Operative States During Rehabilitation. There were important differences between athletes' general motivational style and their most prominent operative states during rehabilitation. For example, both John and Mary reversed from their usual paratelic dominance to being mostly in the telic state while they were in rehabilitation. This change should have been of benefit to their recovery as they set aside their tendency to be paratelic and impulsive and took the rehabilitation seriously, working hard to achieve small improvement goals with the future aim of complete recovery. However, note that John, as a result of a reversal 
from the telic (with conformity) to the paratelic (with negativism) state, actually set his recovery back, when he spontaneously (and against advice) took part in physical activity with his students (see Table 3 and above). For Mary, although she did experience some reversals during rehabilitation, being mostly in a motivational combination of telic, conformist, autic, and mastery states (she was also conformistautic-mastery dominant) may have contributed to her recovery. In addition to being telic about rehabilitation, being in these states would have enabled her to conform to the instructions of medical staff and work hard to improve her personal strength by mastering the tasks given to her by physiotherapists, for example. This state combination (telic-conformist-autic-mastery) was also prominent for Amy during rehabilitation. This required a change from her usual motivational style where she reversed to autic-mastery from her dominant alloic-sympathy states. It appears that being in a state combination of telic-conformist autic-mastery may have assisted Mary and Amy in completing their rehabilitation successfully.

Athletes' Motivational States During Injury. Throughout their rehabilitation, all three participants described times when their injury prevented them from meeting their current motivational needs or stimulated motivational needs that were subsequently not met, resulting in unpleasant and stressful emotional experiences. Not surprisingly, this was particularly evident at times when the autic and mastery states were operative. As Mary (judo) commented, "Well I think it's frustrating a bit well you know doing things like that [motions a small ankle movement] you think oh my god you know is that all the sport I'm going to get?" Similar frustration was expressed by Amy (karate):

I just felt so depressed because I couldn't do anything for myself I mean the first couple of times I had to get someone to wash my hair and carry things for me but I felt really bad about asking people for help so I ended up trying to do it myself.

This was even the case for John (hockey), who more often than not, had the autic and sympathy states operative, never achieving autic-mastery motivation for long: "I want myself to be in the best shape possible for me to do sport ... I want my body, my joints and things like that to be in good shape to enable me to train."

John's desire for a fit, working body was unfulfilled due to his injured state, as was Mary's need to feel personal strength and control over her own body. Similarly, Amy's autic-mastery frustrations focused on her limited athletic capacity, but were also evident in her inability to complete everyday personal activities. The unpleasant experiences brought about by their injuries might have been dissipated if the athletes concerned could have reversed to different states or state combinations. While progress during injury rehabilitation is influenced by a number of personal and contextual factors, it is possible that motivational flexibility (ease of reversals) may be a contributing factor by affecting the athletes' operative states during the rehabilitation period. Future research is required to examine this suggestion as the current exploratory study does not allow causal inferences to be made.

Motivational Flexibility and Difficulty in Reversing. Table 3 depicts the reversals and their inducing agents that were identified within specific time periods during injury rehabilitation for Mary and John. Individual case study discussions above 


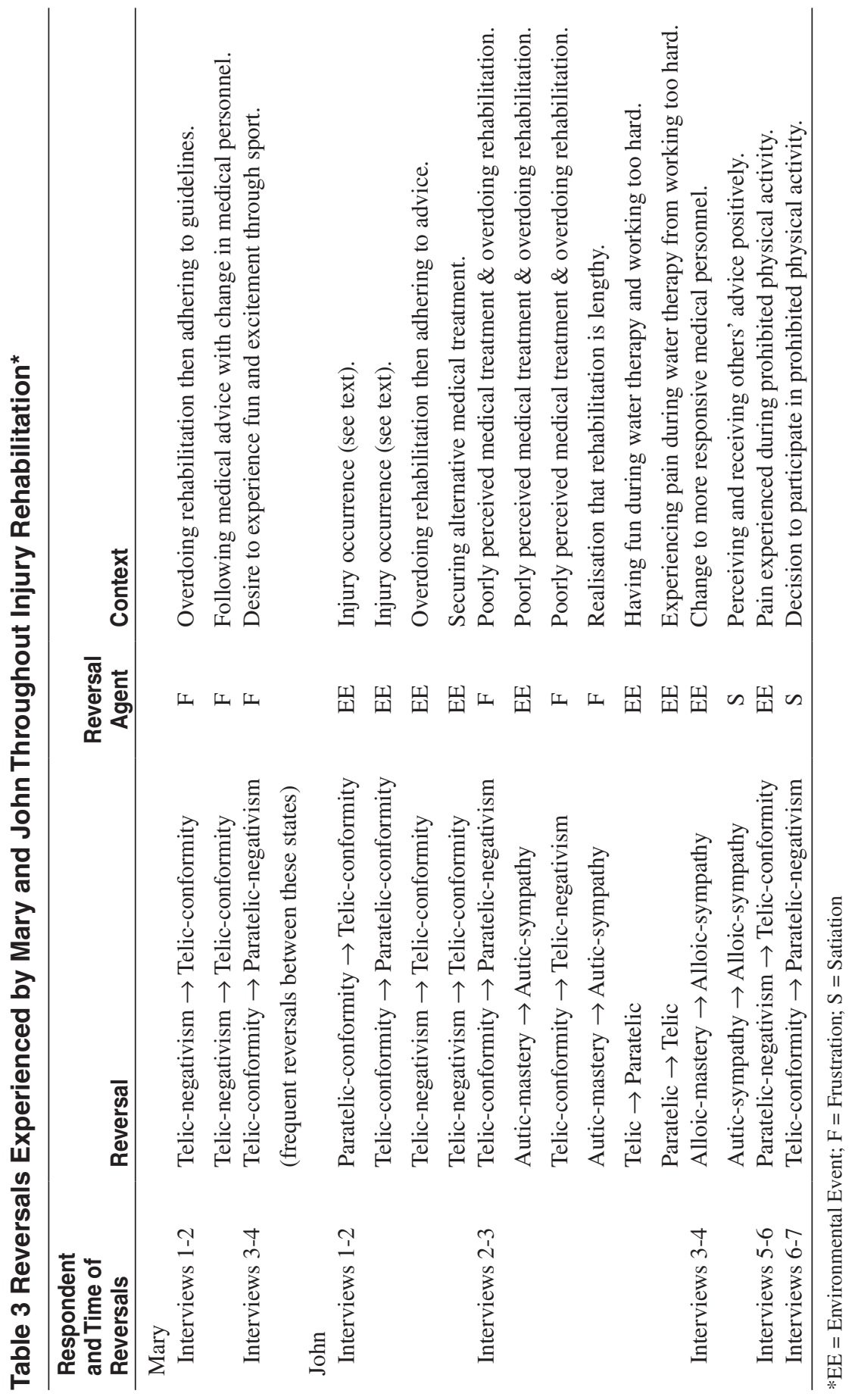


have focused on salient state combinations during specific time periods between interviews. It is clear that all three athletes experienced changes between these time periods in the salience of different state combinations. However, analysis of data describing moment-to-moment reversals that occurred within each of these time periods revealed a different picture.

Results indicated that John (see Table 3) exhibited substantial flexibility between states within specific time periods. In comparison, Mary reported considerably fewer reversals than John did, and Amy reported no reversals between states at all, a possible indication of very limited reversal flexibility (see Table 3). Only John (hockey) and Mary (judo) reported any difficulty in reversing. For example, John's statement below suggests that he was temporarily stuck (reversal inhibition) in the conformist mode, even though he wanted to reverse to a negativistic state:

Yes I do want to get out on the hockey pitch and get playing again I really want to get out there. . . . I'm just hyper, I've got to do something! But I've got to take that time off and ease myself into it rather than risk anything.

Toward the end of her rehabilitation, Mary's comments indicate an inability to reverse from the autic-sympathy state:

I don't know, I just feel like almost as an excuse to do nothing and because I've lost so much in six months and everybody else has progressed. . . . I don't know why I'm so blocked but it definitely is because of the risk of injury.

Reversal theorists have argued that regular reversals among motivational states are necessary for psychological health, and if people become stuck in individual states or combinations of states for long periods, it can lead to clinical problems. ${ }^{29}$ It is possible that while being in the telic-conformist-autic-mastery state, combination may have facilitated Amy's recovery; it may also have been psychologically unhealthy to be in only that particular combination for so long. Unfortunately, however, the authors had no further contact with Amy after rehabilitation and therefore no definite conclusions about any possible detrimental effects can be made.

Interpreting Change Over Time. A central reason for employing a Reversal Theory framework in this study is the emphasis placed within this theory on the dynamic nature of the individual's motivation and subjective experience. Therefore it is important to identify what the current Reversal Theory interpretation tells us about the longitudinal changes in these athletes' responses to athletic injury. First, while injured, all three athletes' most frequently experienced states differed overall from their metamotivational dominance. Whether or not this is causally related to the occurrence of injury could be determined by prospective research designs that sample athletes' most frequently experienced states prior to and following injury, drawing comparisons with their metamotivational dominance. Shifts in most frequently experienced states compared with the athlete's dominant states occurred from the paratelic to telic, alloic to autic, and sympathy to mastery states. These changes are not surprising, given that they indicate an increased focus on the self, on serious, planned activities and on mastery. Clearly, this finding requires replication in future research; however, it is reasonable to speculate on the basis of these preliminary findings that if significant others are aware that throughout the 
injury period the athlete's most prominent motivational orientations may deviate from their usual style, this may help them to deal with behaviors and emotions that may be associated with the athlete's current dominant orientation. For instance, a pervasive autic mastery motivation may result in humiliation, as demonstrated here in Amy's results, during the initial stages of recovery when progress is slow. If significant others are aware of the source of this humiliation, they may be able to help the athlete to meet their autic mastery needs in other ways.

Results obtained here lend support for the motivation-emotion links that are suggested by Reversal Theory. ${ }^{18}$ This adds to our current knowledge on athletes' emotional responses to injury in two ways. While previous studies have described these emotional responses, the Reversal Theory framework used in the current study offers a way of interpreting and understanding the origins of these emotions. In addition, current results highlight the salience of emotions other than those commonly reported (eg, frustration and depression ${ }^{1}$ ) to include emotions such as resentment and virtue, therefore extending our knowledge of the range of emotions experienced by injured athletes.

In line with Reversal Theory principles, we would not expect all three athletes to exhibit the same motivation profiles and changes in these profiles over time; indeed, this was not the case. As discussed above, the degree to which athletes experienced different motivational states over time differed between individuals. When we consider John's experience, his changes in motivational orientation to paratelic-negativism and alloic-sympathy may have been detrimental to his recovery even though reversals are important for maintaining psychological health. ${ }^{29}$ Again, this suggestion requires further support from future studies, but it may be that for some athletes, changes in motivational state may not be beneficial for their recovery. Nevertheless, we tentatively suggest that considering their benefits for general psychological health, support staff need to recognize that changes to nonadaptive states (eg, paratelic-negativism) can occur and may explain an athlete's unexpected behavior, for instance, non-adherence to rehabilitation. Meeting the athlete's current motivational needs in ways that will not hinder their rehabilitation progress would therefore seem appropriate; some suggestions are provided below.

An awareness of the reversal agents that are likely to facilitate reversals between motivational states may also be useful for support staff. John's profile of reversals (see Table 3) indicates that the majority of reversals he experienced were due to environmental events. Further research is needed to determine intra and interindividual patterns in the agents most likely to induce reversals in this context. Once these reversal agents have been identified, when an athlete is currently experiencing what may be an unproductive motivational orientation for their recovery (eg, paratelic-negativism) support staff may then use an appropriate reversal agent to attempt to induce reversals to a more productive orientation, such as telic-conformity. An example may be a progress review and goal setting session to remind the athlete of their long term recovery goals.

The aim of this preliminary study was to conduct an initial investigation into the application of Reversal Theory for examining athletes' psychological and emotional responses to injury. The study has demonstrated that Reversal Theory does offer a worthwhile theoretical framework for examining, over time, intraindividual responses to injury. This is the first study to employ Reversal Theory within this context and results have indicated that the application of this framework may provide 
a useful way of interpreting and understanding the athlete's experience of injury. For instance, using a Reversal Theory framework allows us to suggest the origins of an athlete's emotional responses on the basis of the operative metamotivational states evident in the athlete's description of his or her experience.

The study's strengths lie in its longitudinal, qualitative approach in revealing rich, in-depth data that allow an interpretation of the athlete's subjective experience over time. Nevertheless, this approach limits the extent to which any findings can be extrapolated to make recommendations for practice or generalizations to other samples. This study does offer evidence that Reversal Theory provides a viable interpretive framework within the context of athletic injury and a platform for future research. A number of observations made in the current study could be investigated to further our understanding of the injury experience in prospective studies that include preinjury measures and control for potentially confounding variables such as sport type, length of injury rehabilitation, and location of the injury. Worthwhile questions that have arisen from the current study include the following: Do the states most frequently experienced during injury differ from preinjury states and the athlete's metamotivational dominance? What are the consequences of any differences between these states? What are the consequences of different metamotivational states and associated emotions for behavior and recovery outcomes? Do common reversal agents operate during injury? What are the consequences of reversal inhibition for the athlete's psychological, emotional, and behavioral responses to injury? Can we employ interventions to help athletes to manage their emotional and metamotivational states to optimize recovery outcomes? We would urge researchers to employ Reversal Theory in future attempts to understand the athlete's experience of injury, as this preliminary study has demonstrated that this framework is a fruitful way of interpreting this phenomenon.

\section{References}

1. Gould D, Udry E, Bridges D, Beck L. Down but not out: athlete responses to seasonending injuries. J Sport Exerc Psychol. 1997;19:229-248.

2. Pearson L, Jones G. Emotional effects of sports injuries: implications for physiotherapists. Physiother. 1992;78:762-770.

3. Weiss MR, Troxel RX. Psychology of the injured athlete. J Athletic Training. 1986;21:104-109.

4. Gordon S, Lindgren S. Psycho-physical rehabilitation from a serious sport injury: a case study of an elite fast bowler. Aust J Sci Med Sport. 1990;22:71-76.

5. Laubach WJ, Brewer BW, Van Raalte JL, Petitpas AJ. Attributions for recovery and adherence to sport injury rehabilitation. Aust J Sci Med Sport. 1996;28:30-34.

6. Morrey MA, Stuart MJ, Smith AM, Wiese-Bjornstal DM. A longitudinal examination of athletes' emotional and cognitive responses to anterior cruciate ligament injury. Clin J Sport Med. 1999;9:63-69.

7. Tracey J. The emotional response to the injury and rehabilitation process. J Appl Sport Psychol. 2003;15:279-293.

8. Wiese-Bjornstal DM, Smith AM, Shaffer SM, Morrey MA. An integrated model of response to sport injury: psychological and sociological dynamics. J App Sport Psychol. 1998;10:46-69.

9. Vergeer I. Exploring the mental representation of athletic injury: a longitudinal case study. Psychol Sport Exerc. 2006;7:99-114. 
10. Podlog L, Eklund RC. A longitudinal investigation of competitive athletes' return to sport following serious injury. J Appl Sport Psychol. 2006;18:44-68.

11. Males JR, Kerr JH, Thatcher J, Bellew E. Team process and players' psychological responses to failure in a national volleyball team. Sport Psychol. 2006;20:275-294.

12. Ryan RM, Deci EL. Self-determination theory and the facilitation of intrinsic motivation, social development, and well-being. Am Psychol. 2000;55:68-78.

13. Brewer BW. Review and critique of models of psychological adjustment to athletic injury. J Appl Sport Psychol. 1994;6:89-100.

14. Pargman D, ed. Psychological Bases of Sport Injuries. Morgantown, WV: Fitness Information Technology; 1993.

15. Udry E, Gould D, Bridges, Beck L. Down but not out: athlete responses to seasonending injuries. J Sport Exerc Psychol.;19:229-248.

16. Evans L, Hardy L. Sport injury and grief responses: a review. J Sport Exerc Psychol. 1995;17:227-245.

17. Apter MJ. The Experience of Motivation: The Experience of Psychological Reversals. London: Academic Press; 1982.

18. Apter MJ, ed. Motivational Styles in Everyday Life: A Guide to Reversal Theory. Washington, DC: American Psychological Association; 2001.

19. Lewis G, Svebak S. The psychophysiology of metamotivation. In: Apter MJ, ed. Motivational Styles in Everyday Life: A Guide to Reversal Theory. Washington, DC: American Psychological Association; 2001:97-118.

20. Coddington RD, Troxell JR. The effect of emotional factors on football injury rates: a pilot study. J Hum Stress. 1980;6:3-5.

21. Apter MJ, Mallows R, Williams S. The development of the Motivational Style Profile. Pers Individual Differences. 1998;24:7-18.

22. Kerr JH, Au CKF, Lindner KJ. Motivation and level of risk in male and female recreational sport participation. Person Individual Differences. 2004;37:1245-1253.

23. Taylor AH, May S. Development of a survey to assess athletes' sports injury rehabilitation beliefs. Proceedings of the Annual European Society for Health Psychology Conference. Brussels; 1993.

24. Dale GA. Existential phenomenology: emphasizing the experience of the athlete in sport psychology research. Sport Psychol. 1996;10:307-321.

25. Brukner P, Khan K. Clinical Sports Medicine. 2nd ed. New York: McGraw-Hill; 2001.

26. Males JR, Kerr JH, Gerkovich MM. Metamotivational states during canoe slalom competition: a qualitative study using reversal theory. J Appl Sport Psychol. 1998;10:185200.

27. Hudson J, Walker NC. Metamotivational state reversals during match play golf: an idiographic approach. Sport Psychol. 2002;16:200-217.

28. Johnston LH, Carroll D. The context of emotional responses to athletic injury: a qualitative analysis. J Sport Rehabil. 1998;7:206-220.

29. Lafreniere KD, Ledgerwood DM, Murgatroyd SJ. Psychopathology, therapy and counseling. In: Apter MJ, ed. Motivational Styles in Everyday Life: A Guide to Reversal Theory. Washington, DC: American Psychological Association; 2001:251-285. 
Copyright of Journal of Sport Rehabilitation is the property of Human Kinetics Publishers, Inc. and its content may not be copied or emailed to multiple sites or posted to a listserv without the copyright holder's express written permission. However, users may print, download, or email articles for individual use. 